\title{
Aggressive Plasmablastic Myeloma With Extramedullary Cord Compression and Hyperammonemic Encephalopathy: Case Report and Literature Review
}

\author{
KINGSLEY DAH ${ }^{1}$, JONATHAN L. LAVEZO ${ }^{2}$ and FATMA DIHOWM ${ }^{1}$ \\ ${ }^{1}$ Department of Internal Medicine, Texas Tech University Health Sciences Center El Paso, El Paso, TX, U.S.A.; \\ ${ }^{2}$ Department of Pathology, Texas Tech University Health Sciences Center El Paso, El Paso, TX, U.S.A.
}

\begin{abstract}
Background: Plasmablastic myeloma is an aggressive subtype of multiple myeloma with overall poor prognosis. Spinal cord compression and hyperammonemic encephalopathy are two grave complications of multiple myeloma with significantly poor survival outcomes. Case Report: A 49-year-old male presented with a 5-day history of worsening abdominal distention with inability to walk, urinate or defecate. Imaging findings of innumerable spinal osteolytic lesions with paraspinal masses coupled with a bone marrow biopsy of $\geq 70 \%$ plasmablasts confirmed the diagnosis of plasmablastic myeloma. Despite spinal decompression surgery, the patient remained paraplegic. Three myeloma-directed chemotherapies failed, eventually leading to him developing hyperammonemic encephalopathy culminating in his death. Conclusion: Plasmablastic myeloma is a rare entity which poses therapeutic challenges especially in patients with negative prognosticators, including high-risk cytogenetic markers, extraosseous involvement with cord compression and hyperammonemic encephalopathy. Early aggressive management with consideration of novel therapeutic alternatives, especially in treatment refractory disease, can be worthwhile.
\end{abstract}

Multiple myeloma (MM) is a malignant neoplastic proliferation of plasma cells within the bone marrow, resulting in local and extra-medullary manifestations. It represents about $17 \%$ of hematologic malignancies but only

This article is freely accessible online.

Correspondence to: Kingsley Dah, MD, Department of Internal Medicine, Texas Tech University Health Sciences Center El Paso, El Paso, TX 79905, U.S.A. Tel: +1 9152158000, e-mail: da1ha@hotmail.com

Key Words: Multiple myeloma, plasmablastic myeloma, spinal cord compression, hyperammonemic encephalopathy.
$1 \%$ of all malignancies, often with a predilection for men (1). The most common presentations include bone pain, anemia, renal failure, and hypercalcemia. Spinal cord compression and hyperammonemic encephalopathy are two rare and grave complications of MM $(2,3)$. Cord compression, often resulting in paresthesia, lower extremity weakness, paralysis, and bladder/bowel dysfunction, is sometimes seen at diagnosis and is associated with significant debility and poor quality of life. On the other hand, hyperammonemia with associated encephalopathy can occur at any time in the disease course and is associated with high rates of myeloma relapse and inpatient mortality $(4,5)$. Plasmablastic myeloma is a subtype of MM in which $\geq 2 \%$ of the clonal plasma cells are morphologically plasmablasts (6). It is a very rare and aggressive MM subtype, seen in about $5-10 \%$ of patients with MM and associated with an overall poor prognosis and survival $(6,7)$. We report the case of a Hispanic male with plasmablastic myeloma who presented with complete paraplegia due to spinal cord compression at diagnosis, eventually developing hyperammonemic encephalopathy culminating in his death.

\section{Case Report}

A 49-year-old male presented to the Emergency Department with a 5-day history of worsening abdominal distention, bilateral lower extremity paralysis and inability to urinate or defecate. He initially developed lower extremity weakness which quickly progressed to paralysis over the 5-day period, prompting hospital presentation. He denied abdominal pain, nausea, vomiting, signs and symptoms of infection, or trauma. Physical examination was significant for abdominal distention with tympani, absent sensation below the level of the umbilicus and flaccid paralysis of the bilateral lower extremities.

Pertinent laboratory findings included normocytic anemia with hemoglobin of $11.3 \mathrm{~g} / \mathrm{dl}$, serum creatinine of $4.6 \mathrm{mg} / \mathrm{dl}$, severe hypercalcemia with serum calcium of $15.9 \mathrm{mg} / \mathrm{dl}$, elevated immunoglobulin (Ig) A at $3720 \mathrm{mg} / \mathrm{dl}$, low IgG 

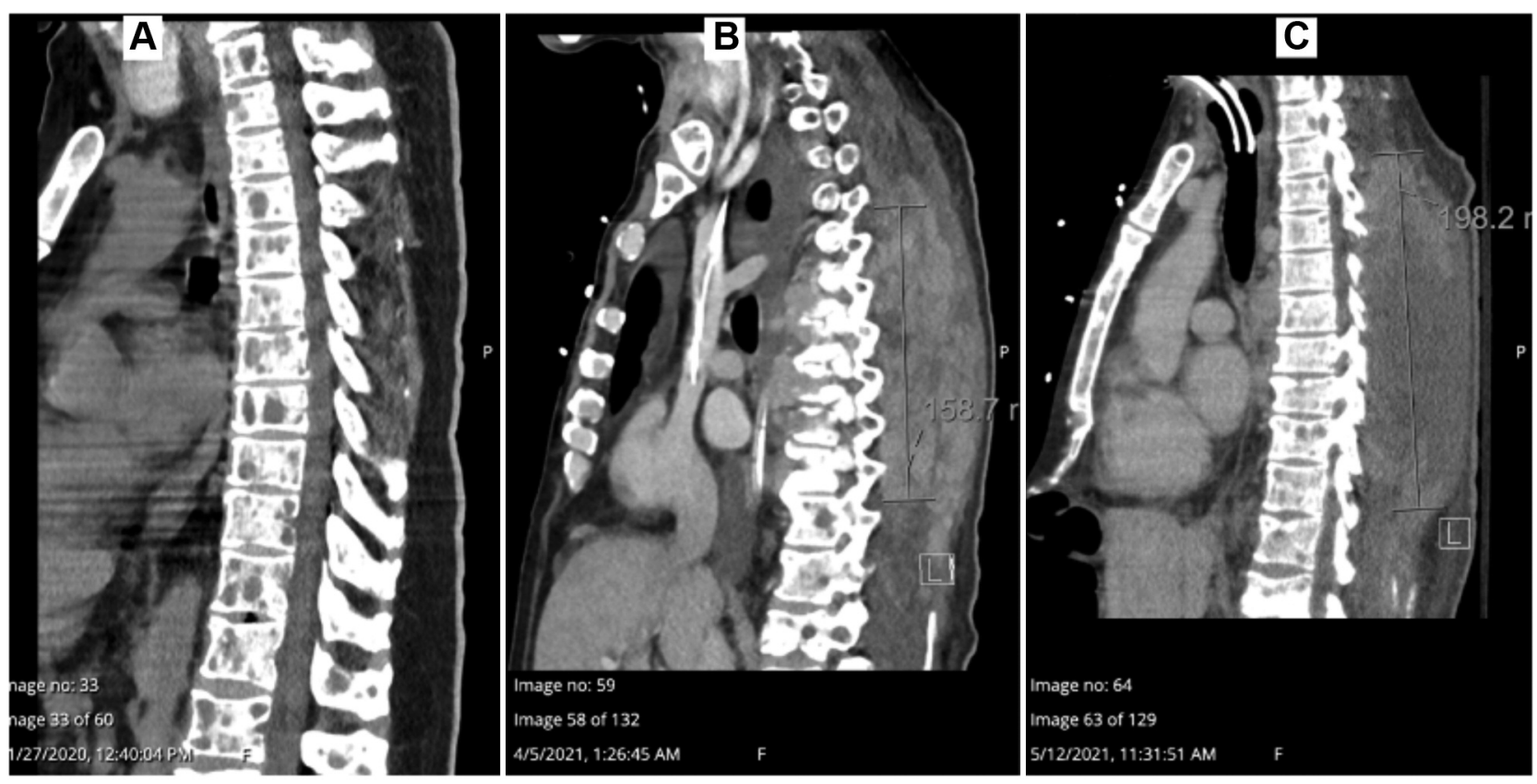

Figure 1. A-C: Computed tomography of the thoracic spine with innumerable lytic lesions involving every thoracic vertebral segment. Right paravertebral soft-tissue mass at T6-7 and T11, with neuroforaminal and possible intraspinal extension. Additional soft-tissue mass involving the left scalene fossa/brachial plexus was present (not shown). Progression of metastatic disease with increased extraosseous soft-tissue components, interval increase in size of large right paraspinal soft-tissue mass with extension through the posterior chest wall (extramedullary involvement) and interval development of multiple new extraosseous soft-tissue nodules, despite extensive chemotherapy.

(385 mg/dl), low IgM (28 mg/dl), elevated M-spike at $3.3 \mathrm{~g} / \mathrm{dl}$ (IgA Kappa monoclonal proteins by immunofixation studies), elevated lactate dehydrogenase of $321 \mathrm{IU} / 1$, elevated beta-2 microglobulin $(61 \mathrm{mg} / \mathrm{l})$, elevated kappa free light chains $(62.1$ $\mathrm{mg} / \mathrm{l})$, normal lambda free light chains $(6.4 \mathrm{mg} / \mathrm{l})$, elevated kappa/lambda ratio (9.7). Computed tomography (CT) imaging revealed innumerable osteolytic lesions involving every segment of the cervical, thoracic, lumbosacral spine and pelvis. There were also multiple exophytic soft-tissue masses involving the thoracic $(\mathrm{T})$ spinal segments (Figure 1), the largest extending to the right paravertebral, intercostal, and right intraspinal epidural spaces from $\mathrm{T} 5$ to $\mathrm{T} 8$ levels, resulting in severe spinal canal stenosis with spinal cord compression and compressive myelopathic changes. No pathological rib or vertebral fractures were evident. Abdominal imaging did not reveal any obstruction or an acute intra-abdominal pathology.

The patient was started on acute treatment for hypercalcemia with aggressive intravenous fluid hydration, calcitonin and pamidronate. Neurosurgery was consulted for emergency cord decompression given plasmablastic infiltration of the thoracic spine. A T6-T8 and partial T9 laminectomy, with partial resection of the intraspinal tumor with decompression of epidural spaces of T6-T9 was performed. Unfortunately, the paraplegia, bladder and bowel functions did not improve. The patients required a chronic bowel regimen for constipation and indwelling Foley catheterization for urinary retention.

Biopsy of the intraspinal lesions showed sheets of proliferating plasmacytoid neoplastic cells (Figure 2) which were positive for cluster of differentiation (CD) markers: CD138+ and CD56+, with slightly more kappa than lambda light chains by immunohistochemical staining (Figure 3). A bone marrow biopsy revealed myelomatous proliferation of plasma cells involving at least $70 \%$ of the marrow, with the plasma cells displaying a plasmablastic morphology (Figure 4). Cytogenetic analysis with fluorescent in situ hybridization showed myeloma-associated chromosomal abnormalities with often unfavorable prognosis: $1 \mathrm{p}$ deletion, additions (1q,19p, and 21p), loss of chromosome 15, 1q tetrasomy, and trisomy of chromosomes $6,7,8,10,11,12$, 17, 19, 20 and 22. These findings were consistent with a diagnosis of multiple myeloma of the plasmablastic subtype with $\operatorname{IgA}$ and kappa light chain predominance. As per the Revised Multiple Myeloma International Staging System (8), he was classed as having stage III disease, corresponding to a 29-month median progression-free survival.

A week after discharge, he was started on anti-myeloma induction chemotherapy with cyclophosphamide, bortezomib 

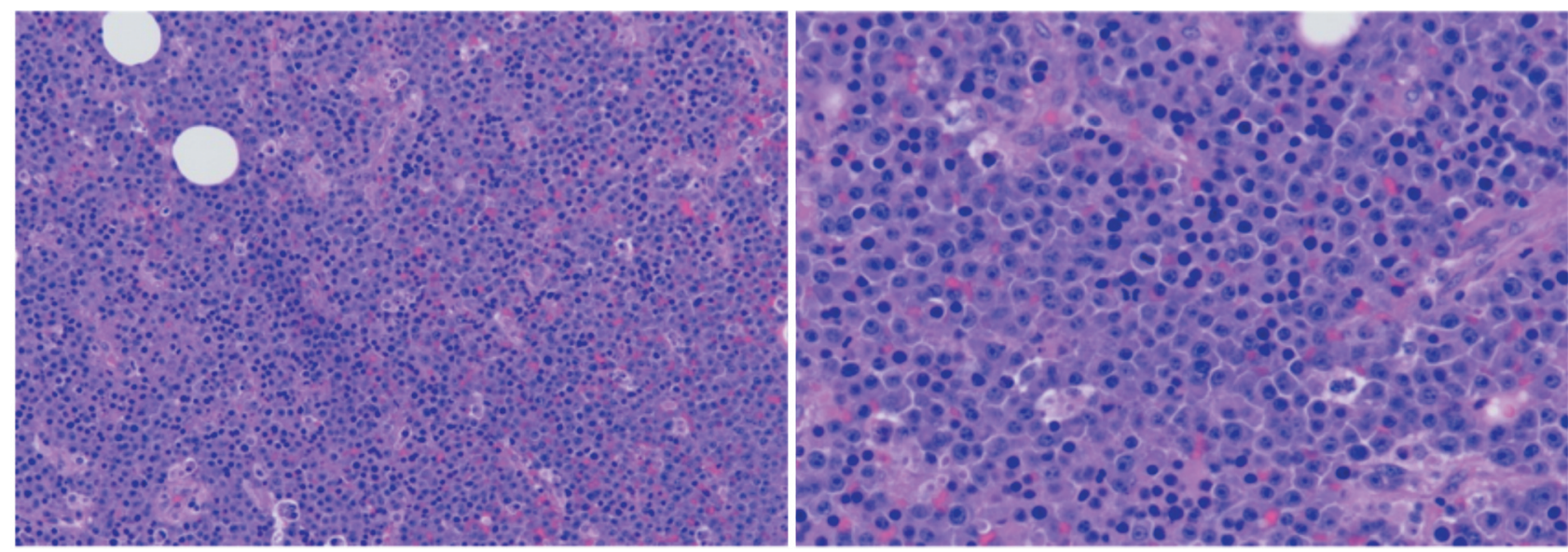

Figure 2. Hematoxylin and eosin-stained sections from spinal surgery showing sheets of plasma cells (left, $\times 200)$ with plasmablastic morphology and increased mitotic activity (right, $\times 400$ ).

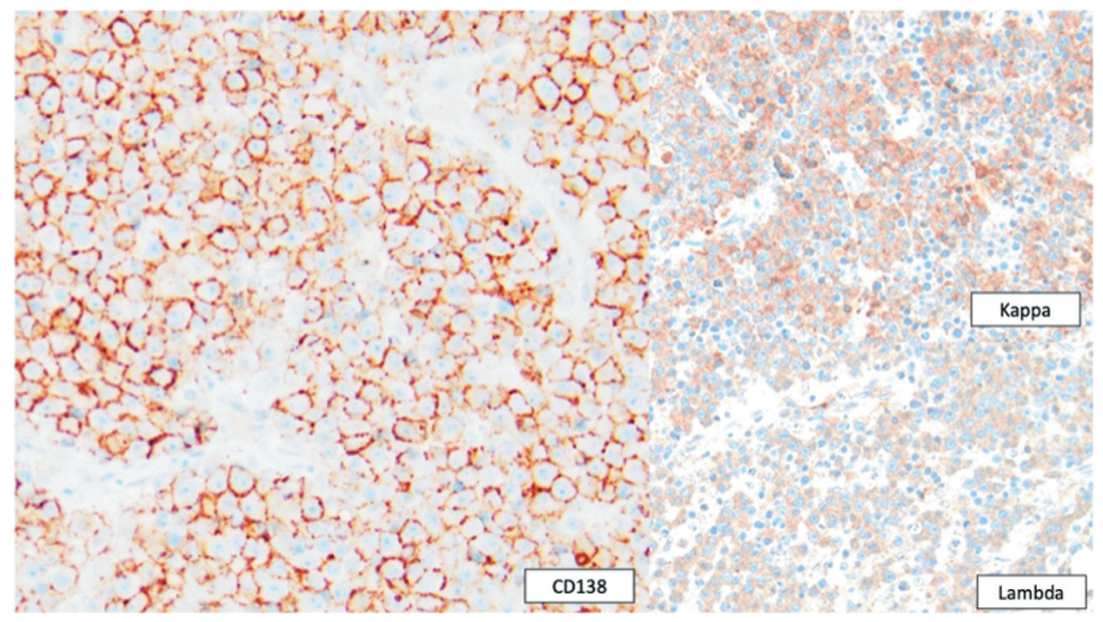

Figure 3. Immunohistochemical stains confirm plasma cell origin with expression of CD138 (left, x400), and slightly more kappa than lambda light chains (right, $\times 400$ ).

and dexamethasone (CyBorD) regimen. After two cycles, the patient's myeloma had shown a positive response as evidenced by a reduction in $\mathrm{M}$ spike to $1 \mathrm{~g} / \mathrm{dl}$; IgA of 762 $\mathrm{mg} / \mathrm{dl}$; free light chains: $31.3 \mathrm{mg} / 1 \mathrm{kappa} 6.67 \mathrm{mg} / 1$ lambda, with a kappa/lambda ratio of 4.74; and serum B2 microglobulin of $3.43 \mathrm{mg} / \mathrm{l}$. This positive response was, however, not matched with overall improvement in clinical outcomes. The patient's clinical course was complicated by recurrent malignant pleural effusions. The patient went on to complete his third cycle of Revlimid (lenalidomide) monotherapy as well as two cycles of etoposide, prednisone, oncovin, cytoxan and doxorubicin (EPOCH) regimen. Repeat CT scans continued to show an increase in size and number of pleural-based implants and ongoing enlargement of paravertebral masses, consistent with disease progression (Figure 1). Surprisingly, however, his M spike continued to decrease to $0.4 \mathrm{~g} / \mathrm{dl}$.

Despite his poor response to both the CyBorD and EPOCH regimens, the patient continued to express his desire for all aggressive treatment options. He completed an additional two rounds of the darzalex/dexamethasone regimen, following which it became clear to the patient and the family that his disease had not responded to any of the three myelomadirected regimens. With the likelihood that further treatments would be futile, the patient stopped further chemotherapy. It was not too long after stopping chemotherapy that the 

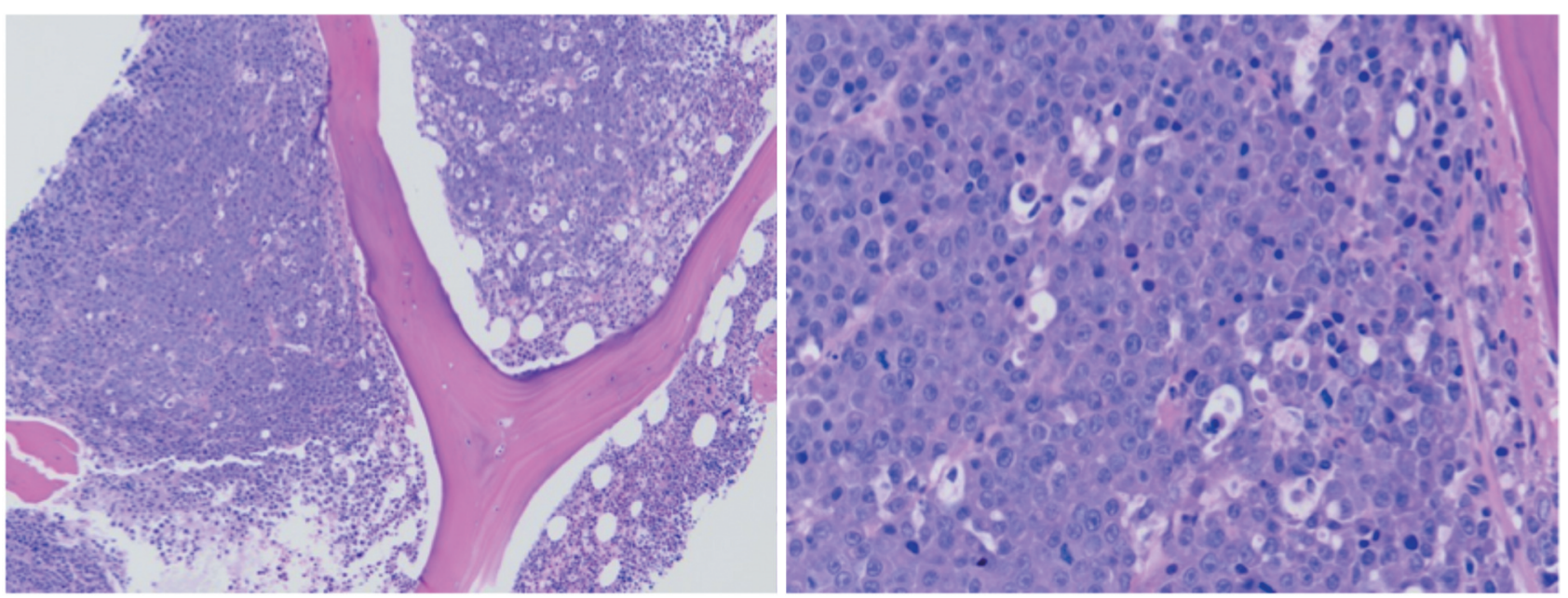

Figure 4. Hematoxylin and eosin-stained sections of bone marrow biopsy showing at least $70 \%$ marrow involvement by plasma cells (left, $\times 100)$ with similar morphology to the spine surgery specimen (right, $\times 400)$.

patient's mentation started to decline, and he became more encephalopathic with the passing of each day. Further encephalopathy workup showed normal serum viscosity, brain CT negative for any acute intracranial pathology and elevated ammonia level at $63.3 \mu \mathrm{mol} / \mathrm{l}$ (normal range: 9-30 $\mu \mathrm{mol} / \mathrm{l})$. With elevated ammonia level, normal serum viscosity and normal neuroimaging, extraosseous intracranial involvement was excluded. Although he had been intermittently hypotensive during his hospitalization, he was responsive to intravenous fluids, albumin infusions, and midodrine. The development of encephalopathy also appeared to parallel the hyperammonemia. Nonetheless, his condition continued to deteriorate, and because he had declined any further measures at this point, no further therapeutic interventions were pursued. The patient passed away shortly thereafter, 6 months after diagnosis.

\section{Discussion}

The clinical manifestations of MM are due to infiltration of bone and other organs by proliferating plasma cells. Although the most common clinical features at diagnosis often include anemia, bone pain, renal failure, and hypercalcemia, extramedullary involvement can be seen in about $4.6 \%$ of MM patients (2). A small number of patients present with severe complications, including spinal cord compression, often requiring a rapid and timely intervention. Overall, about $20 \%$ of patients develop cord compression during their disease and this carries an overall poor prognosis (9). Although pathological compression fractures of the vertebral column due to local involvement are common, extramedullary extension of myelomatous exophytic soft-tissue masses, and less commonly extraosseous epidural myelomas, causing compressive myelopathy can occur $(2,10)$. Our patient presented with acute flaccid paraplegia, bladder, and bowel dysfunction, all a sequelae of cord compression from multiple exophytic masses scattered throughout the thoracic spine. Due to his late presentation, resolution of his neurological deficits could not be achieved despite immediate neurosurgical intervention and appropriate follow-up chemotherapy. This is consistent with many other reported cases which have demonstrated poor recovery of neurological function in patients with cord compression due to extraosseous involvement at presentation or during the course of the disease $(10,11)$. Although rare, some reports have demonstrated a significant improvement in motor function with radiotherapy as well as surgical decompression $(12,13)$. As such, most authors agree that a timely intervention with high-dose steroid, surgery and chemotherapy is key if any neurological recovery is to be anticipated (14).

Plasmablastic MM is a rare entity, and its propensity for extramedullary and extraosseous involvement contributes to its aggressive nature and overall poor survival and outcomes (15). Given its rarity, finding an appropriate regimen can be daunting as there is hardly a clear consensus on management. In general, much success in MM treatment has been seen in recent years with novel induction regimens, which typically include a varied combination of a proteasome inhibitor, immunomodulatory agent, and monoclonal antibodies $(16,17)$. The RVD [Revlimid ${ }^{\circledR}$ (lenalidomide) + Velcade ${ }^{\circledR}$ (bortezomib)+ dexamethasone] and CyBorD regimens, for example, have shown very positive outcomes in MM and are therefore standard of care across the United States $(16,18)$. Other combination 
regimens including monoclonal antibodies such as daratumumab are showing promising results (15).

The effectiveness of a particular regimen can depend on the type of cytogenetic abnormalities identified and the MM subtype. It is now well known that the presence of $17 \mathrm{p}$ deletion and translocations $\mathrm{t}(4 ; 14)$ or $\mathrm{t}(14 ; 16)$ are associated with early disease progression, with very poor myeloma survival outcomes (8). Similarly, chromosome 1q addition $(+1 q)$, one of the most common chromosomal abnormalities seen in MM, has been shown to be an independent negative prognosticator for poor overall survival $(19,20)$. Its negative effect on survival appears to be more profound in the presence of other co-occurring chromosomal abnormalities, such as deletion $1 \mathrm{q}$ or $1 \mathrm{q}$ tetrasomy $(20,21)$. Although our patient had no $17 \mathrm{p}$ deletion or translocations $\mathrm{t}(4 ; 14)$ and $\mathrm{t}(14 ; 16)$, he unfortunately had $+1 \mathrm{q}$ together with deletion $1 \mathrm{q}$ and $1 \mathrm{q}$ tetrasomy. In line with prior studies, this likely played a role in his negative outcome. Given that some prior studies had suggested that the negative prognostic impact of the $+1 \mathrm{q}$ could be overcome with the CyBorD rather than with the RVD regimen $(20,22)$, our patient was initially started on the CyBorD regimen. Although there was a partial initial response with $a \geq 50 \%$ reduction in serum $\mathrm{M}$-protein following the first two rounds of CyBorD, this response was not matched with an overall improvement in clinical outcomes. Granted, there was no reoccurrence of hypercalcemia and azotemia, but his paralysis was permanent, and he required enteral feeding and needed a tracheostomy, consistent with poor long-term functional recovery. It certainly seemed that the negative impact on prognosis of these chromosomal abnormalities had been maintained despite targeted myeloma therapies, as had been demonstrated in prior studies which showed that the presence of $+1 \mathrm{q}$ conferred a significantly negative effect on progression-free and overall survival, even in patients with a positive response to the RVD or CyBorD regimens $(20,23)$.

Ultimately, more studies are needed to fully understand the prognostic effect of the $+1 \mathrm{q}$ chromosome abnormality in patients with MM vis-a-vis the novel anti-myeloma agents. Nevertheless, patients with $+1 \mathrm{q}$ and other co-occurring $+1 \mathrm{q}$ or high-risk cytogenetic abnormalities should be considered at very high risk for early disease progression. Targeting of specific gene mutations with specific compounds appears to be a promising avenue for targeted myeloma therapies, especially in patients refractory to combinations of the above novel agents (24). Multiple clinical trials are ongoing and examining other potential molecular targets including the bispecific T-cell engager (BiTE) molecule and chimeric antigen receptor T-cell therapies directed against CD19, already approved in the treatment of other hematological malignancies (25-27). One such chimeric antigen receptor Tcell product is idecabtagene vicleucel (Ide-Cel, bb2121) currently being evaluated for high-risk and relapsed myeloma in the phase II KarMMa-2 trial (NCT03601078).
The development of acute encephalopathy in patients with myeloma has been reported in the literature, with possible etiologies including hypercalcemia, hyperviscosity, hyperammonemia and direct extra osseus leptomeningeal involvement (3, 28-30). Hyperammonemic encephalopathy, however rare, has been reported as both an initial presentation and late complication of relapsing myeloma, often with very poor survival outcomes. Up to $31 \%$ inpatient mortality in patients who received myeloma-directed therapy and $100 \%$ mortality in untreated patients have been reported $(4,5,31)$. Clinical manifestation includes an acute change in mentation, asterixis, seizures, and a rapid progression to coma and death. Even with modest elevations, hyperammonemia can cause encephalopathy. Median ammonia levels of $114 \mu \mathrm{mol} / 1$ have been reported in MMinduced encephalopathy, with most cases commonly seen in IgA and chemotherapy-resistant myeloma (3, 4). Although the pathophysiology is not fully understood, it is thought that malignant myeloma cells and related factors influence amino acid metabolism resulting in an excess production of ammonia, coupled with plasma cell infiltration of the liver that results in portosystemic shunting of the liver's ability to metabolize the excess ammonia that builds up and results in encephalopathy (32-34).

Our patient with plasmablastic IgA myeloma developed hyperammonemic encephalopathy as a late complication of his disease despite extensive chemotherapy. The prompt initiation of aggressive chemotherapy with regimens including any combination of bortezomib, cyclophosphamide and dexamethasone have resulted in rapid normalization of ammonia levels and reversal of myeloma-associated hyperammonemic encephalopathy. Most of these cases, however, were in patients not previously on chemotherapy and in whom MM and hyperammonemic encephalopathy were present at diagnosis $(32,35)$. These patients were going to begin chemotherapy anyway, suggesting that addressing the underlying malignancy had an overall beneficial effect. Nonetheless, other reports have demonstrated an equally beneficial role of hemodialysis in achieving full recovery, even in those with refractory MM-induced hyperammonemia (36). Unfortunately, our patient did not want to undergo any further treatments. Besides, he was a poor candidate for further chemotherapy giving his already poor response; he was also too hemodynamically unstable to withstand dialysis.

In conclusion, our case illustrates some of the rare complications and management challenges associated with MM. Several myeloma-negative prognosticators including the plasmablastic subtype, high-risk cytogenetic markers, extraosseous and spinal cord compression and the development of hyperammonemic encephalopathy exhibited by our patient conferred on him an extremely poor survival outcome. Patients with $+1 \mathrm{q}$ and other high-risk cytogenetic abnormalities should be considered at very high risk for early 
disease progression and chemotherapy should be tailored accordingly. These patients should be considered for more aggressive management early in the disease course, including consideration for enrolment in clinical trials if possible. Clinicians need to be very aware of the significantly high mortality and poor prognosis associated with the development of hyperammonemic encephalopathy at any point during the course of MM and the alternate treatment modalities that have shown some success. Prompt recognition, workup and intensive management should be prioritized. The search for an optimal therapeutic strategy continues to be daunting but evolving with promise.

\section{Conflicts of Interest}

The Authors have no conflicts of interest to declare.

\section{Authors' Contributions}

Kingsley Dah and Fatma Dihowm contributed to the writing and review of this article. Jonathan L. Lavezo provided images of the pathological slides from the biopsies, and also reviewed the original article.

\section{References}

1 Siegel RL, Miller KD, Fuchs HE and Jemal A: Cancer statistics, 2021. CA Cancer J Clin 71(1): 7-33, 2021. PMID: 33433946. DOI: $10.3322 /$ caac. 21654

2 Damaj G, Mohty M, Vey N, Dincan E, Bouabdallah R, Faucher C, Stoppa AM and Gastaut JA: Features of extramedullary and extraosseous multiple myeloma: a report of 19 patients from a single center. Eur J Haematol 73(6): 402-406, 2004. PMID: 15522061. DOI: 10.1111/j.1600-0609.2004.00331.x

3 Murtaza G, Lu H, Faqah A, Konowitz N, Kuruvilla A and Adhikari S: Multiple myeloma-induced hyperammonemic encephalopathy. J Hematol 6(1): 29-31, 2017. PMID: 32300389. DOI: $10.14740 /$ jh $322 \mathrm{e}$

4 Pham A, Reagan JL and Castillo JJ: Multiple myeloma-induced hyperammonemic encephalopathy: an entity associated with high in-patient mortality. Leuk Res 37(10): 1229-1232, 2013. PMID: 23932549. DOI: 10.1016/j.leukres.2013.07.014

5 Issa N, Blondeau B, Dimicoli-Salazar S, Marit G, Morlat P and Camou F: Hyperammonemic encephalopathy as the presenting feature of a relapsing multiple myeloma. Rev Med Interne 37(8): 567-569, 2016. PMID: 26681106. DOI: 10.1016/j.revmed. 2015.11.003

6 Greipp PR, Leong T, Bennett JM, Gaillard JP, Klein B, Stewart JA, Oken MM, Kay NE, Van Ness B and Kyle RA: Plasmablastic morphology - an independent prognostic factor with clinical and laboratory correlates: Eastern Cooperative Oncology Group (ECOG) myeloma trial E9486 report by the ECOG Myeloma Laboratory Group. Blood 91(7): 2501-2507, 1998. PMID: 9516151.

7 Lorsbach RB, Hsi ED, Dogan A and Fend F: Plasma cell myeloma and related neoplasms. Am J Clin Pathol 136(2): 168-182, 2011. PMID: 21757591. DOI: 10.1309/AJCPENJ68FFBRIYB
8 Palumbo A, Avet-Loiseau H, Oliva S, Lokhorst HM, Goldschmidt H, Rosinol L, Richardson P, Caltagirone S, Lahuerta JJ, Facon T, Bringhen S, Gay F, Attal M, Passera R, Spencer A, Offidani M, Kumar S, Musto P, Lonial S, Petrucci MT, Orlowski RZ, Zamagni E, Morgan G, Dimopoulos MA, Durie BG, Anderson KC, Sonneveld P, San Miguel J, Cavo M, Rajkumar SV and Moreau P: Revised international staging system for multiple myeloma: A report from International Myeloma Working group. J Clin Oncol 33(26): 2863-2869, 2015. PMID: 26240224. DOI: 10.1200/JCO.2015.61.2267

9 Wallington M, Mendis S, Premawardhana U, Sanders P and Shahsavar-Haghighi K: Local control and survival in spinal cord compression from lymphoma and myeloma. Radiother Oncol 42(1): 43-47, 1997. PMID: 9132825. DOI: 10.1016/s0167-8140 (96)01858-0

10 Pandey S, Gokden M, Kazemi NJ and Post GR: Hematolymphoid malignancies presenting with spinal epidural mass and spinal cord compression: a case series with rare entities. Ann Clin Lab Sci 49(6): 818-828, 2019. PMID: 31882434.

$11 \mathrm{Ha}$ KY, Kim YH and Kim HW: Multiple myeloma and epidural spinal cord compression : case presentation and a spine surgeon's perspective. J Korean Neurosurg Soc 54(2): 151-154, 2013. PMID: 24175035. DOI: 10.3340/jkns.2013.54.2.151

12 Dürr HR, Wegener B, Krödel A, Müller PE, Jansson V and Refior HJ: Multiple myeloma: surgery of the spine: retrospective analysis of 27 patients. Spine (Phila Pa 1976) 27(3): 320-4; discussion 325-6, 2002. PMID: 11805699. DOI: 10.1097/00007632-200202010-00023

13 Rades D, Veninga T, Stalpers LJ, Basic H, Rudat V, Karstens JH, Dunst $\mathrm{J}$ and Schild SE: Outcome after radiotherapy alone for metastatic spinal cord compression in patients with oligometastases. J Clin Oncol 25(1): 50-56, 2007. PMID: 17194905. DOI: $10.1200 / J C O .2006 .08 .7155$

14 Jin R, Rock J, Jin JY, Janakiraman N, Kim JH, Movsas B and Ryu S: Single fraction spine radiosurgery for myeloma epidural spinal cord compression. J Exp Ther Oncol 8(1): 35-41, 2009. PMID: 19827269.

15 Suarez-Londono JA, Rohatgi A, Antoine-Pepeljugoski C and Braunstein MJ: Aggressive presentation of plasmablastic myeloma. BMJ Case Rep 13(4): e234436, 2020. PMID: 32265213. DOI: $10.1136 /$ bcr-2020-234436

16 Kumar SK, Rajkumar SV, Dispenzieri A, Lacy MQ, Hayman SR, Buadi FK, Zeldenrust SR, Dingli D, Russell SJ, Lust JA, Greipp PR, Kyle RA and Gertz MA: Improved survival in multiple myeloma and the impact of novel therapies. Blood 111(5): 2516-2520, 2008. PMID: 17975015. DOI: 10.1182/blood-2007-10-116129

17 Kumar SK, Dispenzieri A, Lacy MQ, Gertz MA, Buadi FK, Pandey S, Kapoor P, Dingli D, Hayman SR, Leung N, Lust J, McCurdy A, Russell SJ, Zeldenrust SR, Kyle RA and Rajkumar SV: Continued improvement in survival in multiple myeloma: changes in early mortality and outcomes in older patients. Leukemia 28(5): 1122-1128, 2014. PMID: 24157580. DOI: 10.1038/leu.2013.313

18 Joseph NS, Kaufman JL, Dhodapkar MV, Hofmeister CC, Almaula DK, Heffner LT, Gupta VA, Boise LH, Lonial S and Nooka AK: Long-term follow-up results of lenalidomide, bortezomib, and dexamethasone induction therapy and riskadapted maintenance approach in newly diagnosed multiple myeloma. J Clin Oncol 38(17): 1928-1937, 2020. PMID: 32298201. DOI: $10.1200 / \mathrm{JCO} .19 .02515$ 
19 Walker BA, Leone PE, Chiecchio L, Dickens NJ, Jenner MW, Boyd KD, Johnson DC, Gonzalez D, Dagrada GP, Protheroe RK, Konn ZJ, Stockley DM, Gregory WM, Davies FE, Ross FM and Morgan GJ: A compendium of myeloma-associated chromosomal copy number abnormalities and their prognostic value. Blood 116(15): e56-e65, 2010. PMID: 20616218. DOI: 10.1182/blood-2010-04-279596

20 Schmidt TM, Barwick BG, Joseph N, Heffner LT, Hofmeister CC, Bernal L, Dhodapkar MV, Gupta VA, Jaye DL, Wu J, Goyal S, Chen Z, Boise LH, Lonial S, Nooka AK and Kaufman JL: Gain of Chromosome 1q is associated with early progression in multiple myeloma patients treated with lenalidomide, bortezomib, and dexamethasone. Blood Cancer J 9(12): 94, 2019. PMID: 31767829. DOI: 10.1038/s41408-019-0254-0

21 Costa LJ and Usmani SZ: Defining and managing high-risk multiple myeloma: current concepts. J Natl Compr Canc Netw 18(12): 1730-1737, 2020. PMID: 33285523. DOI: $10.6004 /$ jnccn.2020.7673

22 Smetana J, Berankova K, Zaoralova R, Nemec P, Greslikova H, Kupska R, Mikulasova A, Frohlich J, Sevcikova S, Zahradova L, Krejci M, Sandecka V, Almasi M, Kaisarova P, Melicharova H, Adam Z, Penka M, Jarkovsky J, Jurczyszyn A, Hajek R and Kuglik P: Gain(1)(q21) is an unfavorable genetic prognostic factor for patients with relapsed multiple myeloma treated with thalidomide but not for those treated with bortezomib. Clin Lymphoma Myeloma Leuk 13(2): 123-130, 2013. PMID: 23291040. DOI: 10.1016/j.clml.2012.11.012

23 An G, Xu Y, Shi L, Shizhen Z, Deng S, Xie Z, Sui W, Zhan F and Qiu L: Chromosome 1q21 gains confer inferior outcomes in multiple myeloma treated with bortezomib but copy number variation and percentage of plasma cells involved have no additional prognostic value. Haematologica 99(2): 353-359, 2014. PMID: 24213147. DOI: 10.3324/haematol.2013.088211

24 Offidani M, Corvatta L, Morè S and Olivieri A: Novel experimental drugs for treatment of multiple myeloma. J Exp Pharmacol 13: 245264, 2021. PMID: 33727866. DOI: 10.2147/JEP.S265288

25 Mikkilineni L and Kochenderfer JN: Chimeric antigen receptor T-cell therapies for multiple myeloma. Blood 130(24): 25942602, 2017. PMID: 28928126. DOI: 10.1182/blood-2017-06793869

26 Raje N, Berdeja J, Lin Y, Siegel D, Jagannath S, Madduri D, Liedtke M, Rosenblatt J, Maus MV, Turka A, Lam LP, Morgan RA, Friedman K, Massaro M, Wang J, Russotti G, Yang Z, Campbell T, Hege K, Petrocca F, Quigley MT, Munshi N and Kochenderfer JN: Anti-BCMA CAR T-cell therapy bb2121 in relapsed or refractory multiple myeloma. N Engl J Med 380(18): 1726-1737, 2019 PMID: 31042825 . DOI: 10.1056/NEJMoa1817226

27 Harrison S, Minnema M, Lee H, Spencer A, Kapoor P, Madduri D, Larsen J, Ailawadhi S, Kaufman J, Raab M, Hari P, Iida S, Vij R, Davies F, Lesley R, Upreti V, Yang Z, Sharma A, Minella A and Lentzsch S: A phase 1 first in human (FIH) study of AMG 701, an anti-B-cell maturation antigen (BCMA) half-life extended (HLE) BiTE ${ }^{\circledR}$ (bispecific T-cell engager) molecule, in relapsed/refractory (RR) multiple myeloma (MM). Blood 136(Suppl 1): 28-29, 2021. DOI: 10.1182/blood-2020-134063
28 Sandhu G, Farias AA, Ranade A and Meisels I: Altered mental status in a case of multiple myeloma not related to a metabolic cause. NDT Plus 2(5): 434-435, 2009. PMID: 25949373. DOI: 10.1093/ndtplus/sfp083

29 Jaruvongvanich V, Spanuchart I, O-Charoen P, Kitamura C, Sumida L and Roytman M: An unusual cause of altered mental status in multiple myeloma: an extraosseous manifestation. Hawaii J Med Public Health 75(4): 109-112, 2016. PMID: 27099806.

30 Meena DS, Bohra GK, Garg MK, Purohit A, Kumar D and Tripathi S: Hypercalcemic encephalopathy as an initial presentation of multiple myeloma. Case Rep Emerg Med 2020: 4746865, 2020. PMID: 32089905. DOI: 10.1155/2020/4746865

31 Fernández-Álvarez R, González-García E and Fernández-Álvarez $\mathrm{C}$ : [Hyperammonemic encephalopathy as the presenting feature of multiple myeloma]. Med Clin (Barc) 147(10): 472-473, 2016. PMID: 27567337. DOI: 10.1016/j.medcli.2016.07.004

32 Kwan L, Wang C and Levitt L: Hyperammonemic encephalopathy in multiple myeloma. N Engl J Med 346(21): 1674-1675, 2002. PMID: 12024007. DOI: 10.1056/NEJM200205233462119

33 Cichoż-Lach H and Michalak A: Current pathogenetic aspects of hepatic encephalopathy and noncirrhotic hyperammonemic encephalopathy. World J Gastroenterol 19(1): 26-34, 2013. PMID: 23326159. DOI: 10.3748/wjg.v19.i1.26

34 Upadhyay R, Bleck TP and Busl KM: Hyperammonemia: What urea-lly need to know: Case report of severe noncirrhotic hyperammonemic encephalopathy and review of the literature. Case Rep Med 2016: 8512721, 2016. PMID: 27738433. DOI: $10.1155 / 2016 / 8512721$

35 Howman R, Thakerer A, Pitman M, Ding N, Thompson PA, Khot A and Harrison SJ: Bortezomib, cyclophosphamide, and dexamethasone: highly effective for rapid reversal of myelomaassociated hyperammonemic encephalopathy. Leuk Lymphoma 51(12): 2299-2302, 2010. PMID: 20929329. DOI: 10.3109/ 10428194.2010.518654

36 Brucculeri M, Gabbard W, Masson J and Jooma N: Simultaneous double hemodialysis for the control of refractory hyperammonemia. Int J Artif Organs 36(2): 135-138, 2013. PMID: 23404638. DOI: 10.5301/ijao.5000177
Received September 13, 2021

Revised October 5, 2021

Accepted October 12, 2021 